\title{
Docking simulations and QM/MM studies between isoniazid prodrug, catalase-peroxidase (KatG) and S315T mutant from Mycobacterium tuberculosis
}

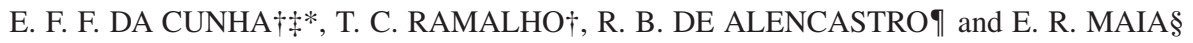 \\ $†$ Departamento de Química, Universidade Federal de Lavras-UFLA, Campus Universitário, Lavras, Caixa Postal \\ 3037, Lavras, MG CEP: 37200-000, Brazil \\ $\ddagger$ Centro Brasileiro de Pesquisas Físicas (CBPF), Rua Dr. Xavier Sigaud, 150, Urca, Rio de janeiro, RJ 22290-180, \\ Brazil \\ | Departamento de Química Orgânica, Instituto de Química, Universidade Federal do Rio de Janeiro, Ilha do Fundão, \\ CT, Bl. A, Lab. 609, Rio de Janeiro, RJ 21949-900, Brazil \\ §LEEM Físico-Química, Instituto de Química, Universidade de Brasília-UnB, Cidade Universitária, Campus \\ Darcy Ribeiro, Brasília, CEP 70919-970-DF, Brazil
}

(Received 3 August 2006; revised 15 February 2007; in final form 20 February 2007)

\begin{abstract}
Isoniazid (INH), an antibiotic used to treat tuberculosis (TB), is a prodrug requiring activation by the Mycobacterium tuberculosis KatG ( $m t \mathrm{KatG})$. In the present work, theoretical calculations were carried out to locate the most energetically-favorable INH-KatG interaction modes using the experimental structure of a wild type and mutant $m t$ KatG active site. The S315T mutation significantly affects the ability of the enzyme to convert INH to isonicotinic acid in vitro. The results showed that significant changes occur in the INH binding pattern when serine is replaced by threonine.
\end{abstract}

Keywords: Isoniazid; Mycobacterium tuberculosis KatG; QM/MM; Docking

\section{Introduction}

Catalase-peroxidases are hemoprotein enzymes involved in the oxidative defense repertoire of cells. They function primarily as catalases to convert two molecules of hydrogen peroxide into water and oxygen via a two-step reaction cycle. The resulting intermediate, compound I (figure 1), is two oxidizing equivalents above the resting state: two electrons having been transferred from the enzyme to the coordinated oxygen atom, one from the iron and the other from either the porphyrin or an amino acid. Catalase-peroxidases also exhibit a peroxidizing pathway that begins with a reaction, similar to that of a catalytic cycle, involving hydrogen peroxide oxidation of the heme iron. The second step involves the reduction of the heme iron in two consecutive one-electron steps via compound II, back to the ferric enzyme [1]. The sequence of reactions is shown in figure 1, in which reaction $\mathbf{A}$ is common to both activities,

*Corresponding author. Email: elaine_cunha@ufla.br; effcid@dacafe.com 


$$
\begin{array}{ll}
\text { enzyme }\left(\mathrm{Fe}^{I I I}\right)+\mathrm{H}_{2} \mathrm{O}_{2} \rightarrow \text { compound I }\left(\mathrm{Fe}^{\mathrm{IV}}\right)+\mathrm{H}_{2} \mathrm{O} & \text { (A) } \\
\text { compound I }\left(\mathrm{Fe}^{I V}\right)+\mathrm{H}_{2} \mathrm{O}_{2} \rightarrow \text { enzyme }\left(\mathrm{Fe}^{I I I}\right)+\mathrm{H}_{2} \mathrm{O}+\mathrm{O}_{2} & \text { (B) } \\
\text { compound I }\left(\mathrm{Fe}^{\mathrm{V}}\right)+\text { donor }(\text { red }) \rightarrow \text { enzyme compound II }\left(\mathrm{Fe}^{I \mathrm{~V}}\right)+\text { donor }(\mathrm{ox}) & \text { (C) } \\
\text { compound II }\left(\mathrm{Fe}^{\mathrm{IV}}\right)+\text { donor }(\text { red }) \rightarrow \text { enzyme }\left(\mathrm{Fe}^{I I I}\right)+\text { donor }(\mathrm{ox}) & \text { (D) }
\end{array}
$$

Figure 1. In the first step $\mathrm{H}_{2} \mathrm{O}_{2}$ is used in the formation of Compound I (reaction A). Compound I reacts with a second $\mathrm{H}_{2} \mathrm{O}_{2}$ reducing the enzyme back to the ferric state (reaction B). In the peroxidase reaction, Compound I is transformed into Compound II (reaction C) and this is reduced back to ferric peroxidase (reaction D).

and is followed by reaction $\mathbf{B}$ in the catalytic pathway, or reactions $\mathbf{C}$ and $\mathbf{D}$ in the peroxidizing pathway:

Mycobacterium tuberculosis $\mathrm{KatG}$ ( $m t \mathrm{KatG}$ ), a catalase-peroxidase containing 80-kDa subunits with one heme per subunit in the dimer, is homologous to yeast, cytochrome $c$ peroxidase in the $\mathrm{N}$-terminal region, especially in the distal and proximal heme regions [2,3]. It is responsible for the activation of the anti-tubercular drug isonicotinic acid hydrazine (isoniazid, INH), and is important for survival of Mycobacterium in macrophages [4].

M. tuberculosis (MTB) is a leading cause of infectious disease in the world today [5]. This outlook, particularly in developing countries, eastern Europe and Asia [6,7], is aggravated by a growing number of tuberculosis (TB) infections in immunocompromised individuals as a result of HIV infections. In addition, the emergence of multiple drug resistant (MDR) strains of MTB is a serious threat to the control of this disease. Thus, even though a variety of drug therapies for the treatment of tubercular infections have been developed over the last 40 years, the research for non-traditional strategies to develop new treatments for TB is still a current concern of the scientific community.

INH remains one of the most effective antibiotics against TB, while the number of INH and other drug-resistant strains has increased dramatically [8]. Even though the mechanism of action of INH is even now not fully understood, it has been clearly demonstrated that it is a prodrug requiring activation by the M. tuberculosis KatG enzyme [9]. However, none of the stable derivatives observed in the KatG-dependent INH conversion, e.g. isonicotinic acid, isonicotinamide and isonicotinaldehyde (figure 2), have demonstrated any bactericidal effect [10]. However, experimental studies suggest that the activated form of INH is probably the isonicotinoyl radical [11]. This nucleophilic radical reacts with the cofactor $\mathrm{NAD}^{+}$, yielding a potent inhibitor of the enoyl-ACP reductase (InhA) [12]. The inhibition of InhA affects the mycolic acid synthesis pathway of the Mycobacterium [13].

It is a well known fact that mutations in KatG are one of the major mechanisms in Mycobacterium INH resistance [14]. Therefore, the replacement of the amino acid Ser-315 in KatG is one of the most commonly found occurrences in clinical INH-resistant strains [15,16]. More than half of INH-resistant clinical isolates carry the S315T mutation, which usually results in a 20- to 200-fold increase in minimal inhibitory concentration (MIC) for INH in vivo [17]. Nowadays, the emergence of resistant strains of TB is being considered a serious threat to the control of this disease. Previous efforts have been made by our group to develop nontraditional strategies against TB [18-20]. We believe that the understanding of the mechanism of resistance of INH could contribute significantly to the combat against MTB.

The main specific problem related to the study of processes in enzymes or in solution is associated with the size of the systems being considered: the huge number of electrons and degrees of freedom. For the first problem a reasonable solution is provided by hybrid quantum mechanics/molecular mechanics (QM/MM) strategies [21-23]. 


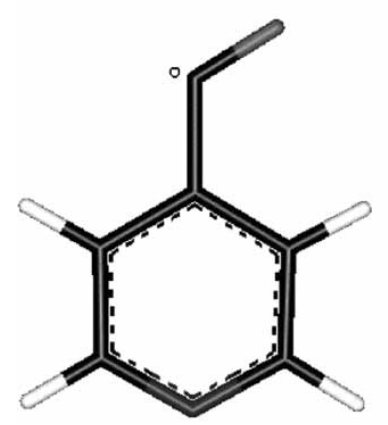

Isonicotinoyl radical

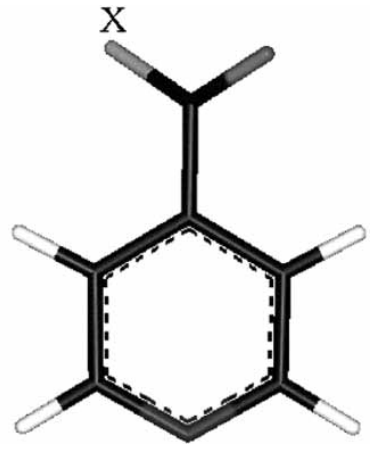

$\mathrm{X}$ : - $\mathrm{NH}-\mathrm{NH}_{2}$ Isoniazide

-H Isonicotialdehyde

$-\mathrm{OH}$ Isonicotinic acid

$-\mathrm{NH}_{2}$ Isonicotinamide

Figure 2. INH and its metabolites observed in the KatG-dependent INH conversion.

Usually, electronic reordering due to breaking and forming bonds is located in a reduced portion of the system. One then needs to describe just the atoms of this region using QM, while the rest of the system is described using MM potentials. The successful application of this methodology is nowadays well reported in the scientific literature [24,25].

This approach allows the explicit inclusion of both steric and electrostatic effects from the protein surroundings. In this work, we used the two-layer ONIOM (QM:MM) method [26]. The interface between the QM region and the MM region is treated by link atoms, and the interaction between the two layers is included at the classical level (mechanical embedding) [27].

Adequate study of such processes must consider the very high dimensionality of the potential energy surfaces involved between the $m t$ KatG (wild type and mutant) and INH. Thus, the present paper describes a computational study on binding modes of INH and KatG enzymes. The analysis of the complex formed by KatG and INH, obtained from docking simulations, were evaluated at $a b$ intio level with QM/MM techniques. We believe the developed model might contribute to the understanding of both the activation process and the mechanism of resistance of INH.

\section{Methodology}

Molecular modeling calculations were performed in Silicon Graphics IndigoII and O2 workstations using the Accelrys software packages: InsightII 98.0 [28], and DISCOVER 2.9.8 (CVFF force field) [29].

\subsection{Preparing protein, refinement and evaluation}

M. tuberculosis wild type (PDB code: 1SJ2 [30] and S315T mutation KatG (PDB code: $2 \mathrm{CCD}$ ) [31] were taken from the Brookhaven Protein Data Bank (PDB). The $m t$ KatG crystal structure was determined to a resolution of $2.4 \AA$. The $m t$ KatG shares $55 \%$ identity and $69 \%$ 
similarity with Haloarcula marismortui $\mathrm{KatG}$ ( $\mathrm{Hm} \mathrm{KatG)}$ and $66 \%$ identity and $77 \%$ similarity with Burkholderia pseudomallei $\mathrm{KatG}$ (Bp KatG).

After hydrogen atoms addition to the crystal structure, the atomic coordinates were minimized by the following protocol, to which constraints and restraints were added in order to gain better control over structural relaxation [32]. The protocol was defined by four successive steps: (i) to eliminate the initial strains, only hydrogen atoms were allowed to move, while the heavy atoms were kept fixed; (ii) for the next adjustments, the enzyme sidechains and the crystal water molecules were tethered restrained, keeping the main-chain atoms and the cofactor heme fixed; (iii) the tethering restraints for the backbone atoms were gradually decreased; and (iv) strains were minimized until the system was completely relaxed $[18,33]$. The 25 heavy atoms composing the heme macro-cycle were kept fixed during third- and fourth-steps of relaxation procedure. One thousand steepest descent minimization steps were carried out, followed by the conjugate gradient minimization method, until the derivatives were of the order of $5.0,1.0,0.5$ and $0.05 \mathrm{~kJ} / \mathrm{mol} / \AA$, respectively.

After the structural relaxation of wild-type $m t \mathrm{KatG}$, water molecules were calculated to complete three shells around the complex. The molecular system was composed of 15.647 atoms, in which the enzyme participated with 10.908 atoms and 717 residues, and the solvent molecules with 4659 water molecules. Then, the complex was slowly relaxed to clean the starting structure. Those steps were necessary to remove bad contacts or internals in the initial rigid structure, reducing distortions risks and conducting to an optimized starting point for the subsequent docking calculations.

\subsection{Docking studies}

Affinity is a program for automatically docking a ligand to a receptor based on the energy of the ligand/receptor complex [34]. According to the Kuntz et al. classification [35,36], this is an energy driven method. Affinity has the ability to offer a very flexible and powerful docking protocol employing molecular dynamics method in conjunction with the Monte Carlo algorithm [37].

2.2.1 Introducing the ligand into the binding pocket. Docking calculations involve some distinct steps. First of all, the wild-type and mutant complexes were refined. Then, the INH compound was driven into the active sites. To perform those steps, the GRID-based method of calculating molecular interaction fields was used to pre-compute and save the information necessary for force field scoring into a grid file. This scoring function approximates molecular mechanics interaction energies, and consists of van der Waals and electrostatic components [28]. During this process, energetically-favorable orientations were allowed to take place and final interaction energies were calculated using the CVFF force field [28,29]. Affinity functionalities subsequently checked the energies and, then, a discover-based energy minimization allowed the interactions optimizations of the final set of structures. Three factors primarily influencing the binding conformation of the ligand/protein complexes were considered for the best score evaluation: binding energies, hydrogen bonding distances, and hydrophobic-hydrophobic interactions [43].

2.2.2 Setting up the ligand conformational analysis into the binding pocket. To perform a conformational analysis of the complexes (wild-type and mutant), the ligand in the context 
of the binding pocket was allowed to move by a random combination of translation, rotation and torsion changes using the Monte Carlo algorithm and molecular dynamics simulation $[18,36]$. Through this procedure, the orientation and the conformational spaces of the ligand with respect to the receptor were both sampled. To perform the molecular dynamics trajectory, the enzyme was partitioned into two subset regions: a dynamic one, which includes all amino acid residues having at least one atom within a radius of $16 \AA$ from the center of mass of the INH ligand; and a static one, composed by the rest of the system. For ligand orientation (random movement), dynamic trajectories at $300 \mathrm{~K}$ were then collected over 200 ps. A dielectric constant of $\varepsilon_{r}=78.5$ and a $12 \AA$ non-bonded cut-off were adopted for all simulations. Finally, the structures resulting from the dynamics trajectory were selected on the basis of root-mean-square deviation (rmsd) and re-optimized using the conjugate gradient method, until the maximum derivative was less than $0.05 \mathrm{~kJ} / \mathrm{mol} / \AA$.

\section{$2.3 Q M / M M$ studies}

In order to investigate the influence of possible restraints on the distance between the proximal histidine and the Fe atom, we have performed QM calculations of the INH binding energy as a function of the distance between the proximal histidine and the porphyrin plane. The model system used in this case was a Fe-porphyrin group and some residues of amino acids from active site. The calculations were performed by calculating the binding energy from docking structures and the porphyrin plane defined as the center of the four $\mathrm{N}_{\text {Porphyrin atoms }}$ coordinated to the $\mathrm{Fe}$ atom. The $\mathrm{Fe}$ atom was free to move during both optimization and simulation. In all cases, the QM calculations were performed at the density functional theory (DFT) level with the Gaussian89 code [38]. DFT methods have shown an excellent performance for medium and large systems and have also proven to be appropriate for biomolecules and, specifically, for heme models [39,40]. Calculations were performed using the generalized gradient approximation functional proposed by Perdew et al. [41]. This combination of functional and basis sets has already been validated for heme models [42]; the optimized structures were improved by including single-point energies using the 6-31+G(d, p) basis set, unscaled zero-point energy, and thermal corrections (at $298.15 \mathrm{~K}$ and $1 \mathrm{~atm}$ ) estimated at the B3LYP/6-31G(d) level from the active site only study.

\section{Results and discussion}

\subsection{Simulations of the drug-enzyme complexes}

The crystallographic enzymes structures were taken as the starting point for the docking study. This structure is the conformation bound to the enzyme active site or the bioactive conformation of the INH. A recent paper has, however, shown that INH could exhibit different binding modes in enzymes [44]. We therefore consider the docking step to be important to establish the preferential orientation of INH in solution within the active site.

In order to check the compatibility between the active site of the $m t \mathrm{KatG}$ minimized, the mutant $m t \mathrm{KatG}$ enzymes were superimposed after the relaxation procedure. The rmsd was computed for the trace atoms $(\mathrm{C} \alpha)$. The alignments between wild-type and mutant $m t \mathrm{KatG}$ gave rmsd values equal to 0.835 . This value indicates a very similar amino acid orientation between wild-type and S315T mutant $m t$ KatG. 
Heme is an almost planar molecule with a strong positive charge on its central iron atom, which lies slightly above the plane of the molecule. Charges on iron were assigned as +2 and +1 but the structures were kept the same. Shukla et al. have observed that both cases, iron (II) and iron (III), gave similar results [45,46]. As the CVFF force field has no good parameterization for iron, the heme structure coming from 1SJ2 crystal determination was used for further calculations. This non-planar conformation is a little more distorted than the domed shape described in the scientific literature [46]. However, as 1SJ2 complex was refined until $1.7 \AA$, we can presume the enzyme needs the distortion found for the heme group. We choose to use X-ray conformation for docking calculations, after submitting this structure to a very fast energy optimization. Twelve conjugate gradient iterations were enough to reach the maximum energy minimization steps supported, before supplementary distortions started to occur. After that, the 25 heavy atoms composing the heme macro-cycle were kept fixed during docking calculations, and the other ones were free to move.

The replacement of Ser315 by Thr in mutant $m t$ KatG has an effect over the active site cavity. The methyl group of Thr315 is oriented toward one of the carboxylic acid of heme group. The effect of this orientation is to reduce the free volume of the cavity, where the ligand will come to. Besides, the residues Pro232, Trp300, Gly316 and Ala348 are slightly displaced compared to their orientation in wild-type $m t$ KatG reducing the entry of the cavity. We could freely interpret this tightening as a selectivity process to the orientation that INH could take before interaction and stabilization into the cavity.

The initial position and conformation of the ligand in the active site of both wild-type and mutant enzymes were taken from crystal coordinates with PDB codes 1SJ2 [30] and 2CCD [31], respectively. The INH position is similar in both wild-type and mutant $m t$ KatG enzymes [47-49]. All reasonable binding orientations for INH were investigated. During the analysis using Affinity, the final structure was accepted or rejected based on energy and similarity criteria to structures found before. Only structures the energy of which were lower than that of the last accepted structure or the Boltzmann factor of which was greater than a random number between 0 and 1 were accepted [37]. In checking structure similarity, the rms distances between the current analyzed structure and structures previously found were computed for ligand atoms. Note that rms distances are different from rms deviations in that the ligand molecule is not translated or rotated in calculating the rms distance (i.e. no superimposition is done). From the $200 \mathrm{ps}$ simulations performed for INH with each enzyme (wild-type and mutant katG), the binding modes with the lowest docked energies were selected.

Following a search of the conformational space of 200 INH different orientations performed using Affinity, the low-energy interaction modes were chosen for further minimization. For wild-type $m t k a t G$, the preferential conformation (WT) selected from docking conformation is presented in figure 3 .

\subsection{Docking of INH into the wild-type mtKatG active site}

The conformation selected from docking calculations was that where the INH was positioned at $180^{\circ}$ to the previous one, the pyridine cycle headed toward the active site cavity followed by its chain. The formed complex was also stabilized by seven hydrogen bonds: the nitrogen atom of the $\mathrm{NH}_{2}$ group of the INH ligand interacts with the oxygen atom of the Asp137 carbonyl group $\left(\mathrm{OH}_{16}(\mathrm{INH}) \ldots \mathrm{CO}_{\mathrm{D} 1}(\mathrm{Asp} 137), 2.14 \AA\right)$; all other hydrogen bonds are formed with the carboxylic acids of the heme group, interacting with the Phe272, Lys274, His276 and Ser315 residues. $\left(\mathrm{COOH}_{2 \mathrm{D}}(\mathrm{Heme}) \ldots \mathrm{CO}(\mathrm{Phe} 272), 1.73 \AA\right.$; 


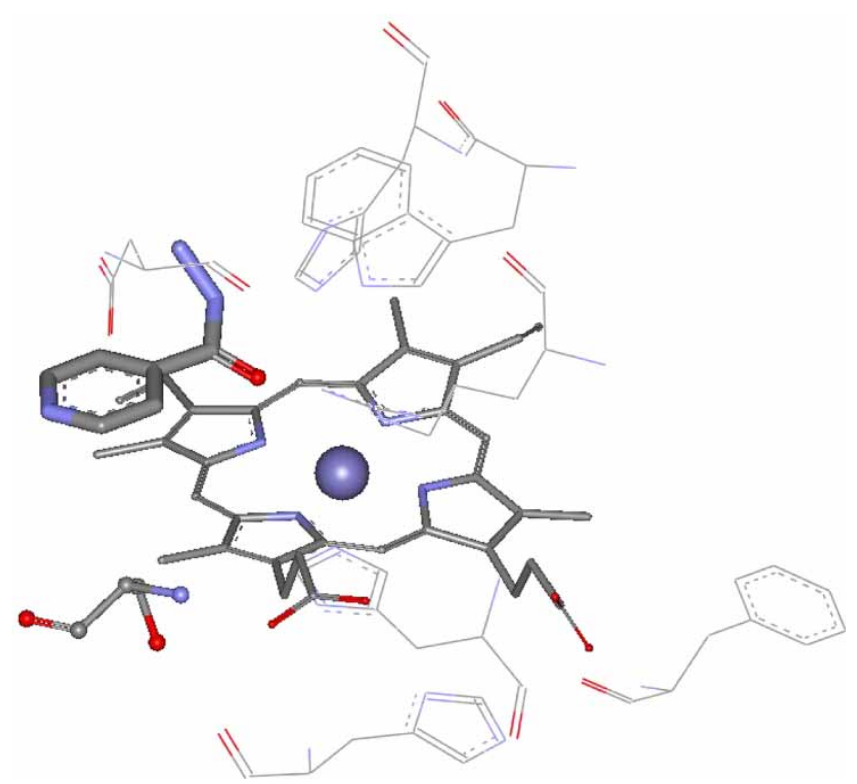

Figure 3. Representation of the complex formed between the wild-type $m t$ KatG (active site) and INH in WT. For clarity, solvent molecules and hydrogen atoms, when not interacting, are not shown.

$\mathrm{HN}\left(\right.$ Lys274)...COO $\mathrm{COO}_{2 \mathrm{D}} \mathrm{H}(\mathrm{Heme}), 2.24 \AA$; $\mathrm{HN}(\mathrm{His} 276) \ldots \mathrm{CO}_{1 \mathrm{~A}} \mathrm{OH}(\mathrm{Heme}), 2.07 \AA$; $\mathrm{N}_{\mathrm{D} 1}(-$ His 276).... $\mathrm{COO}_{2 \mathrm{~A}} \mathrm{H}(\mathrm{Heme}), \quad 2.84 \AA$; $\quad \mathrm{COOH}_{2 \mathrm{~A}}(\mathrm{Heme}) \ldots \mathrm{N}_{\mathrm{D} 1}(\mathrm{His} 276), \quad 1.90 \AA$; $\mathrm{HO}(\mathrm{Ser} 315) \ldots \mathrm{CO}_{\mathrm{D} 1} \mathrm{OH}(\mathrm{Heme}), 2.01 \AA$ ) (table 1). The result of this calculation is shown in the figure 3 . The relative energies calculated for this molecular system are consistent with the preceding results. Also, this orientation is among the most stable docking orientations for the INH ligand. In spite of that, the pyridine portion is less stabilized by $\pi-\pi$ and cation stacking interactions than it was obtained for our first model of orientation.

Table 1. Interactions for docked INH in the four described orientations.

\begin{tabular}{|c|c|c|}
\hline Donor & Acceptor & Distance $(\AA)$ \\
\hline \multicolumn{3}{|l|}{ WT } \\
\hline INH P3: $\mathrm{H}_{16}$ & MT:Asp137: $\mathrm{O}_{\mathrm{D} 1}$ & 2.14 \\
\hline HEME: $\mathrm{H}_{2 \mathrm{D}}$ & MT:Phe272:O & 1.73 \\
\hline MT:Lys274:HN & HEME: $\mathrm{O}_{2 \mathrm{D}}$ & 2.24 \\
\hline MT:His276:HN & HEME: $\mathrm{O}_{1 \mathrm{~A}}$ & 2.07 \\
\hline MT:His276:ND1 & HEME: $\mathrm{O}_{2 \mathrm{~A}}$ & 2.84 \\
\hline HEME: $\mathrm{H}_{2 \mathrm{~A}}$ & MT:His276: $\mathrm{N}_{\mathrm{D} 1}$ & 1.90 \\
\hline MT:Ser315:HG & HEME: $\mathrm{O}_{1 \mathrm{~A}}$ & 2.01 \\
\hline \multicolumn{3}{|l|}{ Muta } \\
\hline INH_P2:H 17 & MUT:Arg104:O & 1.87 \\
\hline HEME: $\mathrm{N}_{\mathrm{B}}$ & INH_P2:O & 2.77 \\
\hline HEME: $\mathrm{H}_{2 \mathrm{D}}$ & MUT:Phe272:O & 1.69 \\
\hline MUT:His276:HN & HEME: $\mathrm{O}_{1 \mathrm{~A}}$ & 2.12 \\
\hline MUT:His276: $N_{D 1}$ & HEME: $\mathrm{O}_{2 \mathrm{~A}}$ & 2.84 \\
\hline HEME: $\mathrm{H}_{2 \mathrm{~A}}$ & MUT:His276: $\mathrm{N}_{\mathrm{D} 1}$ & 1.91 \\
\hline MUT:Thr315: $\mathrm{H}_{\mathrm{G} 1}$ & HEME: $\mathrm{O}_{1 \mathrm{~A}}$ & 2.04 \\
\hline
\end{tabular}




\subsection{Docking of INH into the mutant mtKatG active site}

The docking study for mutant katG gave very similar results, so we chose to discuss only one orientation (Muta) (figure 4). This complex is stabilized by seven hydrogen bonds: the nitrogen atom of $\mathrm{NH} 2$ group of the INH interacts with the oxygen of the Arg104 carbonyl group $\left(\mathrm{NH}_{17}(\mathrm{INH}) \ldots \mathrm{CO}(\operatorname{Arg} 104), 1.87 \AA\right)$; the oxygen atom of the INH carbonyl group interacts with one of the nitrogen atoms of the heme group $\left(\mathrm{N}_{\mathrm{B}}\right.$ (heme)...CO $\mathrm{CO}_{10}(\mathrm{INH})$, $2.77 \AA$ ); the hydroxyl portion of one carboxylic acid of the heme group interacts with Phe272 $\left(\mathrm{COOH}_{2 \mathrm{D}}(\mathrm{Heme}) . . \mathrm{CO}(\mathrm{Phe} 272), 1.69 \AA\right.$; the amino acid His276 forms three hydrogen bonds (HN(His276)... $\mathrm{CO}_{1 \mathrm{~A}} \mathrm{OH}(\mathrm{Heme}), 2.12 \AA ; \mathrm{N}_{\mathrm{D} 1}(\mathrm{His} 276) \ldots \mathrm{COO}_{2 \mathrm{~A}} \mathrm{H}_{2 \mathrm{~A}}(\mathrm{Heme}), 2.84$, $1.91 \AA$ ) and, finally, Thr315 interacts with an oxygen of one of the carboxylic acids (OH(Thr315).... $\left.\mathrm{CO}_{1 \mathrm{~A}} \mathrm{OH}(\mathrm{Heme}), 2.04 \AA\right)$.

Our docking results for $m t$ KatG showed that the interactions formed through the three amino acids, Asp137, Phe272 and His276, were stable and were common to the chosen models. Furthermore, we also observe for WT, a stable hydrogen bond with Ser315. However, when similar calculations were carried out for the mutant $m t \mathrm{KatG}$, the substitution of Thr315 for Ser315 seems to stabilize the complex further through the formation of a hydrogen bond formed by the hydroxyl group of Thr315 and the heme cofactor. Also, the INH positioning now led to a more harmonious complex, favoring $\pi-\pi$ and cation interactions that seemed to contribute to the system stability. However, the interaction between the INH carbonyl group with Asp137 was lost and replaced by an interaction between the INH NH2 with Arg104.

It is known that the mutant $m t$ KatG significantly affects the ability of the enzyme to convert INH to isonicotinic acid in vitro [47]. This fact and the greater peroxidative activity of the wild-type $m t \mathrm{KatG}$, suggests that the two proteins might differ with respect to their electron donor binding sites, and that these differences may be reflected in a small, but possibly real, difference in the distal ligand distance. In addition, spectroscopic

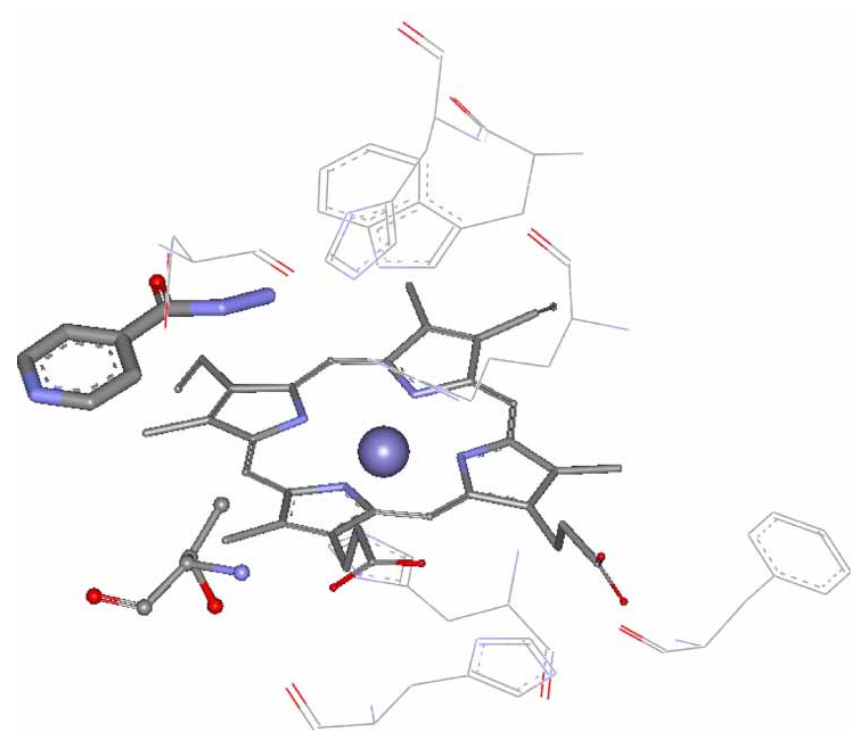

Figure 4. INH docked on the mutant $m t$ KatG binding pocket. For clarity, solvent molecules and hydrogen atoms, when not interacting, are not shown. 
characterization studies of mutant $m t \mathrm{KatG}$ presented a slightly reduced affinity for heme in this mutant [50].

Our molecular simulation results show that the replacement of Ser315 by Thr hinders the approximation of the drug and the heme group, changing the ligand binding profile significantly. This leads to an increase of the electrostatic interaction energy between INH and the mutant protein. The preferred orientation of the pyridine ring should be the one pointing towards the exterior of the active site. INH is stabilized parallel to the heme group in the mutant $m t \mathrm{KatG}$, but this is not so in the wild-type enzyme, where the INH carbonyl group is turned to the inverse side of the propionic side chains of the heme group. In this orientation, an interaction between Thr315 and the heme group turns out to be favored, but the interaction between the INH carbonyl group with Asp137 is lost. Moreover, it seems that this interaction is important for system stability. These considerations give support to our proposal of the orientation model WT as the best model to explain the INH interactions into the active site of $m t \mathrm{KatG}$.

Nowadays, no firm biochemical link between the many KatG variants and INH resistance has been established. In the present study, we have shown the existence of steric hindrance between INH, and $m t$ KatG or the S315T mutant. Our results are in agreement with similar recent findings [50,51].

\subsection{QM/MM calculations}

The QM region for the three-dimensional models for the KatG structure was optimized with the two-layer ONIOM method [52], implemented in the Gaussian 98 program [38]. In these QM/MM calculations, a specified region around the active center was calculated with a QM method, while the rest of the protein was treated at an MM level. The QM region can describe the essential bond-cleaving and bond-forming processes in the enzyme, while the MM region can promote interactions with the $\mathrm{QM}$ region through partial charges and van der Waals forces of atoms in the MM region. At the QM/MM border, atoms in the MM region bound to an atom in the QM region were replaced by hydrogen atoms in the QM-level part of the QM/MM calculation. The QM region includes the iron atom and their surrounding amino acid residues. We decided to obtain the QM region by surrounding INH with a sphere of $15 \AA$ centered at the $\mathrm{Fe}$ atom, including some residues of amino acids from active site [53-55]. The QM calculations were performed with the B3LYP method, which consists of the Slater exchange, the Hartree-Fock exchange, the exchange functional of Becke, the correlation functional of Lee, Yang and Parr (LYP), and the correlation functional of Vosko et al. [56]. This DFT method is an improved version of B3LYP and able to reasonably evaluate relative energies between high-spin and low-spin states of transition-metal complexes in general. The method of choice for MM calculations is the Amber force field (Amber96). From table 2 (single point calculations with QM/MM method) the model more stable for INH orientation (WT) was used. This result had shown a very good agreement with docking energy calculation. This means that the orientations and hydrogen bonds of INH with $m t$ KatG in solution found in the docking step using Affinity program are reasonable and agree very well with the experimental orientation of INH [30]. Using QM/MM methodology, we intended to evaluate the electronic contribution on interaction in the active site of the enzymes. Thus, the selected orientations (WT and Muta) from docking calculations were then submitted to electrostatic charge calculations; the electrostatic charges were determined so as to reproduce the $\mathrm{B} 3 \mathrm{LYP} / 6-31+\mathrm{G}(\mathrm{d}, \mathrm{p})$ quantum molecular mechanical electrostatic potential (MEP). This means that it was necessary to produce charges that fit into the 
Table 2. Orbital interaction energies ( $\Delta \mathrm{E} 2)$ for wild-type and S315T mutant.

\begin{tabular}{lcc}
\hline & Acceptor/donor & Energy (kcal/mol) \\
\hline Wild-type & $\mathrm{d}_{\mathrm{Fe}}^{*} / \mathrm{n}_{\mathrm{O}}$ & 0.79 \\
& $\sigma_{\mathrm{C}-\mathrm{O}}^{*} / \mathrm{n}_{\mathrm{Fe}}$ & 0.30 \\
& $\sigma_{\mathrm{C}-\mathrm{N}}^{*} / \mathrm{n}_{\mathrm{O}}$ & 35.20 \\
& $\sigma_{\mathrm{C}-\mathrm{C}}^{*} / \mathrm{n}_{\mathrm{O}}$ & 24.00 \\
Mutant S315T & $\mathrm{d}_{\mathrm{Fe}}^{*} / \mathrm{n}_{\mathrm{O}}$ & 0.05 \\
& $\sigma_{\mathrm{C}-\mathrm{O}}^{*} / \mathrm{n}_{\mathrm{Fe}}$ & - \\
& $\sigma_{\mathrm{C}-\mathrm{N}}^{*} / \mathrm{n}_{\mathrm{O}}$ & 18.84 \\
& $\sigma_{\mathrm{C}-\mathrm{C}}^{*} / \mathrm{n}_{\mathrm{O}}$ & 13.33 \\
\hline
\end{tabular}

electrostatic potential at points selected according to the CHelpG scheme $[57,58]$. There is an increase in the atomic charge of the metal center; it is likely due to charge transference from metal center to INH. Geometry optimization at QM/MM level results in dissociation of $\mathrm{CO}(\mathrm{INH})$ and consequently formation of a radical intermediate. Turning now to mutant enzyme, significant differences were obtained in relation to wild-type: for instance, it might be noted that the electron donor binding sites is less intense and geometry optimization did not resulted in dissociation. Thus, we performed the charge calculation in order to get more insight into this. We also observed that the electrostatic charges (ChelpG scheme) were affected: a significant increase from mutant to wild-type enzyme.

Therefore, in wild-type $m t$ KatG active site, the convalency was significantly higher than that computed in mutant $m t \mathrm{KatG}$. In line with this observation, we can conclude that the main contribution for the difference between wild-type and mutant S315T from MTB is apparently steric hindrance between INH and or the S315T mutant in origin.

To get a picture of the chemical bonding in active site model structures from both wildtype and mutant enzymes, we undertook a detailed NBO analysis for each structure at its ground-state. That effect can be explained by means of second-order perturbation theory, which estimates the stabilization as the ratio between the square of the Fock matrix element and the energy difference between the interacting orbitals [59-61]. The energy difference between donor ( $\mathrm{nFe}$ ) (heme group) and acceptor $\left(\sigma^{*}\right.$ or $\left.\mathrm{d}_{\mathrm{Fe}}^{*}\right)$ orbitals of INH in the denominator decrease from mutant to wild-type enzyme (table 2).

In fact, the participation of non-bonded electrons plays an important role in the stabilization of the complex between INH and catalase-peroxidases KatG of $M$. tuberculosis (both wild-type and S315T). An extra stabilization was observed due to $\mathrm{d}_{\mathrm{Fe}}^{*} / \mathrm{n}_{\mathrm{O}} ; \sigma_{\mathrm{C}-\mathrm{O}}^{*} / \mathrm{n}_{\mathrm{Fe}} ; \sigma_{\mathrm{C}-\mathrm{N}}^{*} / \mathrm{n}_{\mathrm{O}}$ and $\sigma_{\mathrm{C}-\mathrm{C}}^{*} / \mathrm{n}_{\mathrm{O}}$ interactions (table 2 ). These interactions are about $0.74 ; 0.30 ; 16.36$ and 10.67 , respectively, in wild-type more effective in the stabilization than in S315T. Consequently, in that case, a higher charge transfer can occur. It is in exact agreement with experimental data, which demonstrated that the S315T mutation significantly affects the ability of the enzyme to convert INH to isonicotinic acid (figure 2) in vitro [31,42]. It should be kept in mind, then: the strong mutation effect is likely due to different INH orientation in S315T. The weaker interaction generated between INH and mutant $m t$ KatG active site must not allow the charge transfer from enzyme $\left(\mathrm{Fe}^{\mathrm{III}}\right)$ to INH and the consequent dissociation of $\mathrm{CO}(\mathrm{INH})$ and final formation of a radical intermediate. 


\section{Conclusion}

M. tuberculosis wild-type (PDB code: 1SJ2) [30] and S315T mutation KatG (PDB code: 2CCD) [31] were taken from the PDB. These molecules were useful to hypothesize an explanation for the most commonly encountered resistance against INH, caused by a specific point mutation. Our calculations have shown that INH binds preferentially near the heme group of the wild-type enzyme and that the addition of a methyl group from threonine residue in the mutant enzyme causes significant changes on the INH binding pattern. The observed differences may be critical for the activation of INH and thus, for drug action. Thus, the formation of a radical intermediate is not observed. We strongly feel that this study may prove to be helpful in the understanding of the molecular interactions and the structural factors responsible for INH resistance.

\section{Acknowledgements}

We are grateful to the Brazilian agencies CNPq, CAPES, FAPERJ, FAPEMIG, FUJB and PRONEX/CNPq nb.(661028/1998-4) for funding part of this work. We are especially grateful to Prof. Carlos Kleber Zago de Andrade for his comments and editing of the manuscript. Finally, we would like to thank to CENAPAD-SP for the computational facilities.

\section{References}

[1] Powers, L., Hillar, A. and Loewer, P.C., 2001, Biochimica et Biophysica Acta: Proteins Structure and Molecular Enzymology, 44, 1546-1555.

[2] Welinder, K.G., 1991, Biochimica et Biophysica Acta, 215, 1080-1092.

[3] Rouse, D.A. and Morris, S.L., 1995, Infection and Immunity, 63, 1427-1435.

[4] Kremer, L., Dover, L.G., Morbidoni, H.R., Vilcheze, C., Maughan, W.N., Baulard, A., Tu, S.C., Honore, N., Deretic, V., Sacchettini, J.C., Locht, C., Jacobs, W.R. and Besra, G.S., 2003, The Journal of Biological Chemistry, 278, 10547-10556.

[5] Blanchard, J.S., 1996, Annual Review of Biochemistry, 65, 215-241.

[6] Roth, B. and Stammers, D.K., 1992, In: C.R. Beddell (Ed.) The Design of Drugs to Macromolecular Targets (New York: John Wiley \& Sons Ltd.).

[7] Raviglione, M.C., Zinder, D.E. and Kochi, A., 1995, Journal of the American Medical Association, 273, $220-245$.

[8] Zhang, Y., Garbe, T. and Young, D., 1993, Molecular Microbiology, 8, 521-528.

[9] Zhang, Y., Heym, B., Young, D. and Cole, S., 1992, Nature, 358, 591-598.

[10] Welinder, K.G., 1992, Current Opinion in Structural Biology, 2, 388-395.

[11] Johnsson, K., Schultz, P.G. and King, D.S., 1995, Journal of the American Chemical Society, 17, 5009-5012.

[12] Rozwarski, D.A., Grant, G.A., Barton, D.H.R., Jacobs, W.R. and Sacchettini, J.C., 1998, Science, 98, 279-283.

[13] Slayden, R.A., Lee, R.E. and Barry, C.E., 2000, Molecular Microbiology, 38, 514-519.

[14] Heym, B., Alzari, P.M., Honore, N. and Cole, S.T., 1995, Molecular Microbiology, 15, 235-247.

[15] Cockerill, F.R., Uhl, J.R., Temsgen, Z., Zhang, G.Y., Stockman, L., Roberts, G.D., Williams, D.L. and Kline, B.C., 1995, The Journal of Infectious Diseases, 171, 240-246.

[16] van Soolingen, D., de Haas, P.E.W., van Doorn, H.R., Kuijper, E., Rinder, H. and Borgdorff, M.W., 2000, The Journal of Infectious Diseases, 182, 1788-1796.

[17] Yu, S.W., Girotto, S., Lee, C. and Magliozzo, R.S., 2003, The Journal of Biological Chemistry, 278, $14769-14778$.

[18] da Cunha, E.F.F., Ramalho, T.C., de Alencastro, R.B. and Maia, E.R., 2004, Journal of Biomolecular Structure and Dynamics, 22(2), 119-130.

[19] da Cunha, E.F.F., Ramalho, T.C. and de Alencastro, R.B., 2004, Journal of Molecular Structure (Theochem), 676, 149-153.

[20] da Cunha, E.F.F., Albuquerque, M.G. and de Alencastro, R.B., 2004, Journal of Molecular Modeling, 10, 297-304. 
[21] Warshel, A. and Levitt, M., 1976, Journal of Molecular Biology, 103, 227-231.

[22] Gao, J., 1995, In: K.B. Lipkowitz and D.B. Boyd (Eds.) Methods and Applications of Combined Quantum Mechanical and Molecular Mechanical Potentials (New York: VCH Inc.).

[23] Gao, J. and Truhlar, D.G., 2002, Annual Review of Physical Chemistry, 53, 467-476.

[24] Martı, S., Andre's, J., Moliner, V. and Silla, E., 2003, Chemistry-A European Journal, 9, 984-991.

[25] Garcia-Viloca, M., Gao, J., Karplus, M. and Truhlar, D.G., 2004, Science, 303, 186-193.

[26] Galva'n, I.F., Sa'nchez, M.L., Martı'n, M.E., Olivares del Valle, F.J. and Aguilar, M.A., 2003, The Journal of Chemical Physics, 118, 255-264.

[27] Galva'n, I.F., Martín, M.E. and Aguilar, M.A., 2004, Journal of Computational Chemistry, 25, 1227-1235.

[28] Accelrys Inc., 9685 Scranton Road, San Diego, CA 92121-3752, USA.

[29] Dauber-Osgutorpe, P., Roberts, V.A. and Osgutorpe, D.G., 1988, Proteins, 4, 31-42.

[30] Bertrand, T., Eady, N.A.J., Jones, J.N., Nagy, J.M., Jamart-Gregoire, B., Raven, E.L. and Brown, K.A., 2004, The Journal of Biological Chemistry, 37, 38991-38999.

[31] Zhao, X.B., Yu, H., Yu, S.W., Wang, F., Sacchettini, J.C. and Magliozzo, R.S., 2006, Biochemistry, 45, 4131-4140.

[32] Yamada, Y., Fujiwara, T., Sato, T., Ygarashi, N. and Tanaka, N., 2002, Nature Structural Biology, 9, 691-695.

[33] Mackay, H.J., Cross, A.J. and Hagler, A.T., 1990, In: G.D. Fasman (Ed.) Prediction of Protein Structure and the Principles of Protein Conformation, Ch. 7 (New York \& London: Plenum Press), pp. 317-358.

[34] Vriend, G., 1990, Journal of Molecular Graphics, 8, 52-57.

[35] Affinity 2000, Accelrys Inc., 9685 Scranton Road, San Diego, CA 92121-3752, USA.

[36] Kuntz, I.D., Blaney, J.M., Oatley, S.J., Langridge, R. and Ferrin, T.E., 1982, Journal of Molecular Biology, 161, 269-274.

[37] Meng, E.C., Shoicket, B.K. and Kuntz, I.D., 1992, Journal of Computational Chemistry, 13, 505-513.

[38] Frisch, M.J., Trucks, G.W., Schlegel, H.B., Scuseria, G.E., Robb, M.A., Cheeseman, J.R., Zakrzewski, V.G., Montgomery, J.A., Stratmann, R.E., Burant, J.C., Dapprich, S., Millam, J.M., Daniels, A.D., Kudin, K.N., Strain, M.C., Farkas, O., Tomasi, J., Barone, V., Cossi, M., Cammi, R., Mennucci, B., Pomelli, C., Adamo, C., Clifford, S., Ochterski, J., Petersson, G.A., Ayala, P.Y., Cui, Q., Morokuma, K., Salvador, P., Dannenberg, J.J., Malick, D.K., Rabuck, A.D., Raghavachari, K., Foresman, J.B., Cioslowski, J., Ortiz, J.V., Baboul, A.G., Stefanov, B.B., Liu, G., Liashenko, A., Piskorz, P., Komaromi, I., Gomperts, R., Martin, R.L., Fox, D.J., Keith, T., Al-Laham, M.A., Peng, C.Y., Nanayakkara, A., Challacombe, M., Gill, P.M.W., Johnson, B., Chen, W., Wong, M.W., Andres, J.L., Gonzalez, C., Head-Gordon, M., Replogle, E.S. and Pople, J.A., Gaussian, Inc., Pittsburgh, PA, 1998.

[39] Singh, U.C. and Kollman, P.A., 1984, Journal of Computational Chemistry, 5, 129-134.

[40] Besler, B.H., Merz, K.M. Jr. and Kollman, P.A., 1990, Journal of Computational Chemistry, 11, 431-436.

[41] Gustin, D.J., Mattei, P., Kast, P., Wiest, O., Lee, L., Cleland, W.W. and Hilvert, D., 1999, Journal of the American Chemical Society, 121, 1756-1765.

[42] Rutkowska-Zbik, D. and Witko, M., 2006, Journal of Molecular Catalysis A: Chemical, 258, 376-380.

[43] Luty, B.A., Wasserman, Z.R., Stouten, P.F.W., Hodge, C.N., Zacharias, M. and McCammon, J.A., 1995, Journal of Computational Chemistry, 16, 454-462.

[44] Argyrou, A., Vetting, M.W. and Aladegbami, B., 2006, Nature Structural and Molecular Biology, 13, 408-413.

[45] Rodriguez, R., Chinea, G., Lopez, N., Pons, T. and Vriend, G., 1998, CABIOS, 14, 523-528.

[46] Shukla, K.L., Gund, T.M. and Meshnick, S.R., 1995, Journal of Molecular Graphics, 13, 215-224.

[47] Kiefl, C., Sreerama, N., Haddad, R., Sun, L., Jentzen, W., Lu, Y., Qiu, Y., Helnutt, J.A. and Woody, R.W., 2002, Journal of the American Chemical Society, 124(13), 3385-3394.

[48] Connolly, M.L., 1991, Journal of Computational Chemistry, 15, 37-45.

[49] Connolly, M.L., 1992, Biopolymers, 32(9), 1215-1236.

[50] Wengenack, N.L., Uhl, J.R., Amand, A.L., Tomlinson, A.J., Benson, L.M., Naylor, S., Kline, B.C. and Cockerill, F.R., 1997, The Journal of Infectious Diseases, 176, 722-734.

[51] Wengenack, N.L., Todorovic, S., Yu, L. and Rusnak, F., 1998, Biochemistry, 37, 15825-15834.

[52] Maseras, F. and Morokuma, K., 1995, Journal of Computational Chemistry, 16, 1170-1179.

[53] Ramalho, T.C., de Alencastro, R.B. and Figueroa-Villar, J.D., 2004, Biophysical Chemistry, 110, 267-279.

[54] Ramalho, T.C., da Cunha, E.F.F. and de Alencastro, R.B., 2004, Journal of Physics Condensed Matter, 16, $6159-6170$.

[55] Ramalho, T.C. and Taft, C.A., 2005, The Journal of Chemical Physics, 123, 054319-0544326.

[56] Vosko, S.H., Wilk, L. and Nusair, M., 1980, Canadian Journal of Chemistry, 58, 1200-1211.

[57] Singh, U.C. and Kollman, P.A., 1984, Journal of Computational Chemistry, 5, 129-145.

[58] Goldman, P., Koch, R.L. and Yeung, T.C., 1986, Biochemical Pharmacology, 35, 43-51.

[59] Wang, P., Zhang, Y.L. and Streitwieser, A., 1991, Journal of the American Chemical Society, 113, 55-64.

[60] Ramalho, T.C. and Figueroa-Villar, J.D., 2003, International Journal of Quantum Chemistry, 95, 267-273.

[61] Salzneer, U. and Schleyer, P.V.R., 1993, Journal of the American Chemical Society, 115, 10231-10236. 


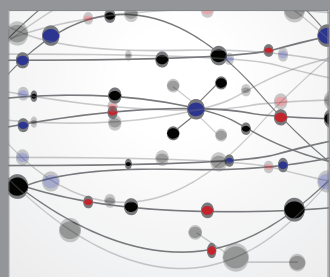

The Scientific World Journal
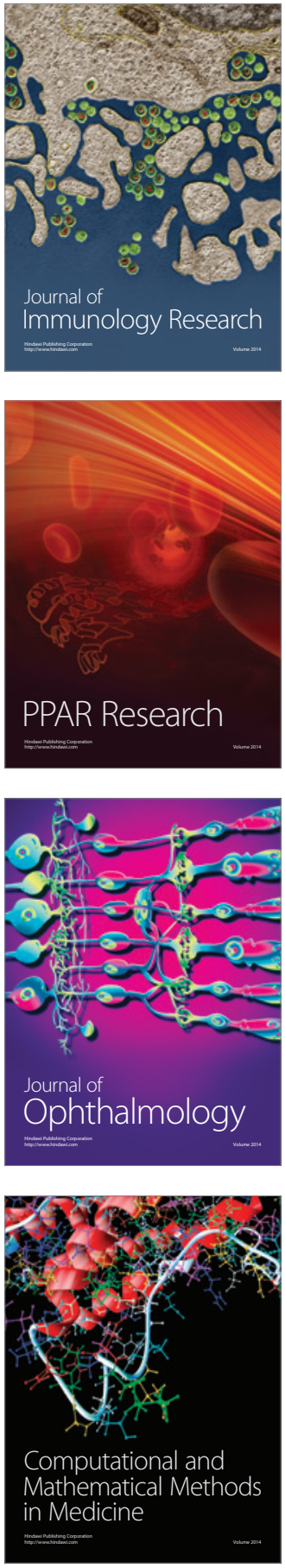

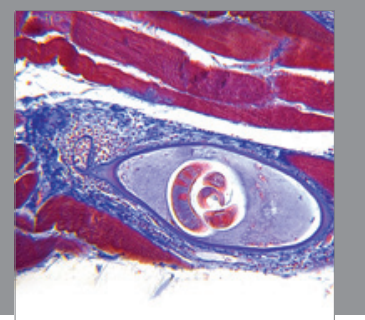

Gastroenterology

Research and Practice
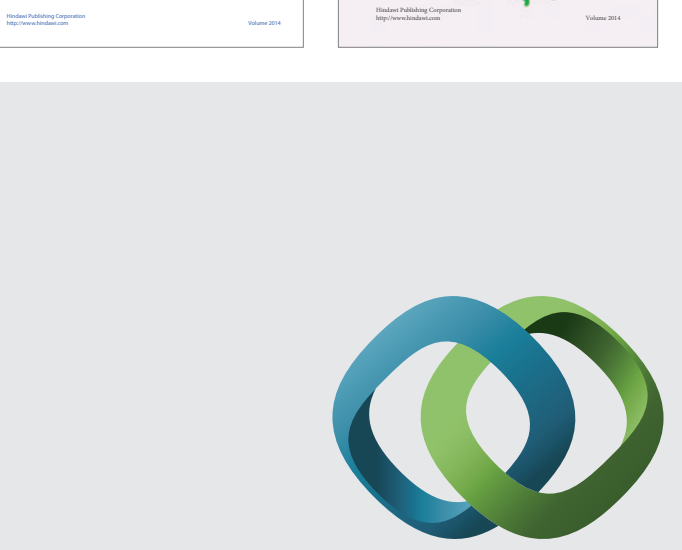

\section{Hindawi}

Submit your manuscripts at

http://www.hindawi.com
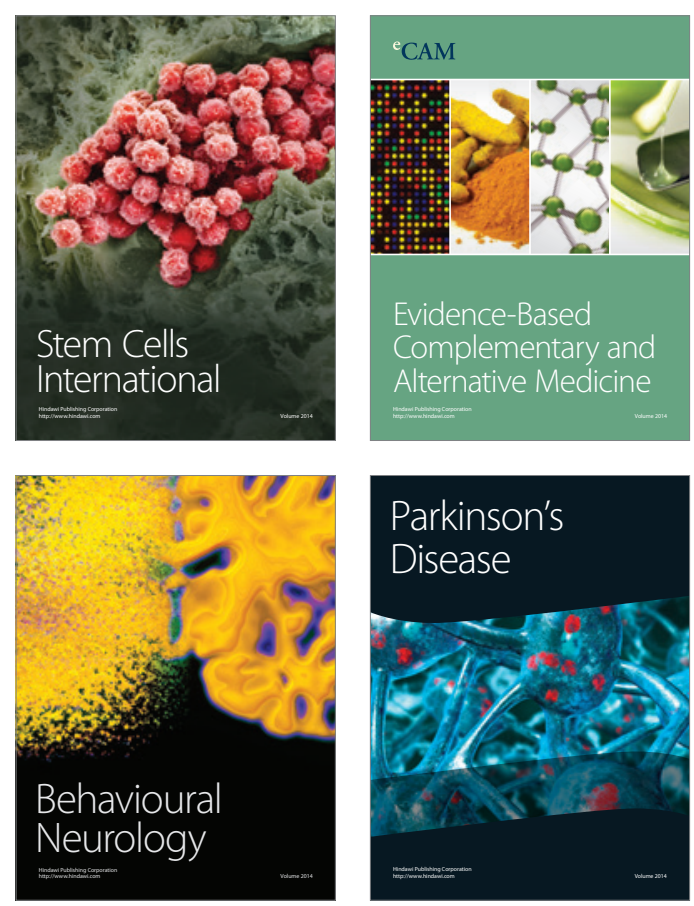

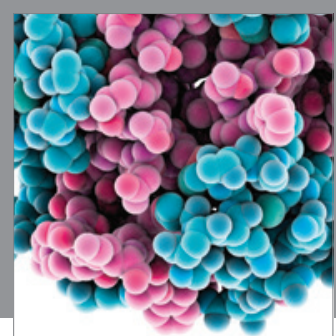

Journal of
Diabetes Research

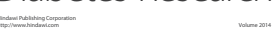

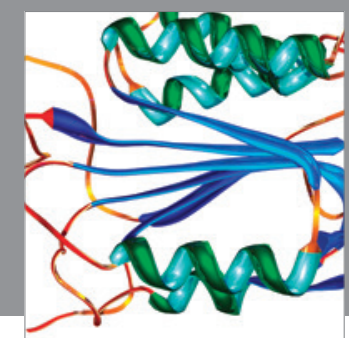

Disease Markers
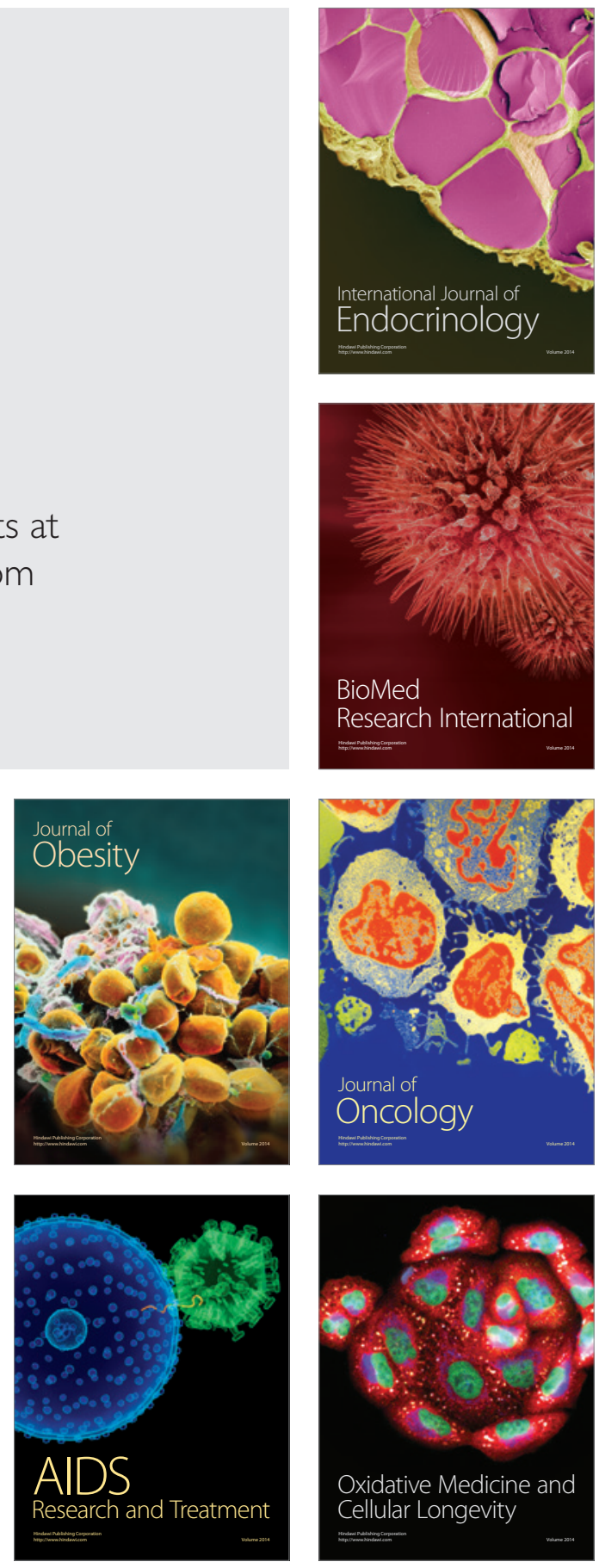